\title{
The Use of UAVs for Performing Safety-Related Tasks at Post-Disaster and Non-Critical Construction Sites
}

\author{
Alessio Calantropio (D) \\ Lab G4CH—Laboratory of Geomatics for Cultural Heritage, DAD—Department of Architecture and Design, \\ Politecnico di Torino, Viale Mattioli, 39, 10125 Torino, Italy; alessio.calantropio@polito.it
}

Received: 29 June 2019; Accepted: 20 September 2019; Published: 27 September 2019

\begin{abstract}
Thanks to the wide diffusion of unmanned aerial vehicles (UAVs), geomatics solutions have actively contributed to the field of safety enhancement and disaster risk reduction, supporting rapid mapping and documentation activities of the damages that have occurred to heritage buildings after natural disasters (such as earthquakes) where, in this scenario it is even more important to plan and execute disaster assessment and response operations in safe conditions. In fact, the planning and execution of technical countermeasures in a seismic emergency response involve higher risks for the safety of the operators as compared with responses related to the activities performed at non-critical construction sites. After an analysis of the state of the art, this study aims to underline the possibilities offered by the use of UAVs for performing safety-related tasks, both at post-disaster and non-critical construction sites. First, a survey has been conducted concerning the main user expectations and characteristics that an ideal UAV platform should have in order to perform safety-related tasks at construction sites that are created following the initial emergency phases. The answers that were obtained have been compared with similar studies retrieved from the literature validating previously conducted research. The legislative context is also considered, as it is an important factor that influences the applicability of these platforms and technology. Along with a method for assessing and mitigating the intrinsic risk of using an UAV, the results of a survey submitted to experts in the field of safety at construction sites is also discussed, intending to identify requirements of the ideal platform and the related user expectations. The results are reported, together with a summary of considerations on the use of these strategies in the analyzed contexts.
\end{abstract}

Keywords: UAVs; construction site; safety assessment; risk exposure reduction; survey; geomatics; seismic emergency; damage assessment

\section{Introduction}

The international scientific community has been involved, especially recently, in studying the effects of natural disasters and in researching and proposing strategies and solutions for their mitigation and reduction. With the goal of refining the understanding of disaster risk in all its extents of exposure, vulnerability, and hazard characteristics, the United Nations Office for Disaster Risk Reduction (UNISDR) has adopted, in 2015, the Sendai Framework (2015-2030) [1], which is a review of the already existing implementation outlined in the Hyogo Framework for Action 2005-2015 [2]. The new chart focuses on understanding disaster risk, managing disaster governance, investing in disaster risk reduction for resilience, and enhancing disaster preparedness for an effective response.

According to its guiding principles, although the primary responsibility for prevention and reduction of disaster risk belongs to the States, only cooperation between central Government and national authorities, sectors and investors, and global partnership and collaboration can effectively assure the protection of the people and the development of their resilience [3]. Following this principle, after the 2016 Central Italy Earthquake [4,5], several Italian Universities collaborated and 
still cooperate with first responders (FR) for the evaluation of emergency response applications for disaster management (DM) and damage assessment (DA) operations. Among these, the Task Force of Politecnico di Torino, led by Professor Sebastiano Foti, in collaboration with the Geotechnical Extreme Events Reconnaissance (GEER) association and the student team, DIsaster RECovery Team (DIRECT), has been involved in emergency expeditions of rapid mapping and metric survey [6], supporting the efforts of the Corpo Nazionale dei Vigili del Fuoco-Italian National Firefighters Corps (CNVVF) on early impact, emergency monitoring, and response operations [7].

In this and other similar scenarios, the growing use of unmanned robots, and especially unmanned aerial vehicles (UAVs), has been relieving humans from the dull, dirty and dangerous jobs, and their usage has been extensively employed in DM operations all around the world. Apart from the very first operations of DM in the aftermath of a natural disaster, which are mainly focused on emergency actions, early response and search and rescue activities, the use of UAVs could also be applied in the subsequent phases of DA, debris removal, building consolidation, and reconstruction which could, in fact, benefit from the use of this emerging technology. Even if this is a promising and interesting research path, examples of this kind of application are currently scarce, experimental, or not yet standardized.

\subsection{Research Aims and Paper Structure}

For the abovementioned reasons, this study aims to underline the possibilities offered from the use of UAVs for performing safety-related tasks, both at post-disaster and non-critical construction sites. First, an investigation has been carried out about the main user expectations and characteristics that an ideal UAV platform should have in order to perform safety-related tasks at construction sites that are created following the initial emergency phases. This investigation has been conducted through a survey, with the help of experts in the field of safety and health at the construction industry, and the obtained answers have been compared with similar studies retrieved from the reference literature. This research confirmed the findings of $[8,9]$ in a group of professionals from a different home country than the countries in the reference literature. It appeared that, although the surveyed population might have differences in the cultural and professional background (related to different concepts of safety in their home country, and to different regulation environments concerning the use of UAVs), the results obtained were quite similar, and the few differences have been discussed in a dedicated discussion paragraph of this paper. The answers obtained in the survey were helpful for defining user expectations, that have also been discussed and compared with the current regulatory environment, together with the range of solutions currently offered by the drone industry. After the discussion of the results, and in the perspective of future adoption of such unmanned systems in the operative practices, a procedure for the prediction, evaluation, and mitigation of the severity and the probability of operational risks connected with the introduction of these new platforms has been proposed. Conclusions, with the benefits and limits of the use of UAVs in the discussed contexts, are summarized and outlined, with the aim of underlining the possibilities offered from the use of these platforms for performing safety-related tasks, both at post-disaster and non-critical construction sites.

\subsection{Differences between Post-Disaster and Non-Critical Construction Sites}

For a better definition of the research context and the related issues, two kinds of constructions sites that are usually started after a disaster have been categorized as post-disaster and non-critical.

As reported in [10], one of the major differences between post-disaster and non-critical construction sites is the higher debris removal risk, usually preeminent in the first kind. In fact, in these activities, debris removal has, as a consequence, had the higher related management costs $(40 \%$ of all disaster-related costs). The activities carried out at post-disaster construction sites mainly concerns technical measures for emergency response and are usually coordinated by firefighters (FR) and civil protection. They include (but are not limited to) DA, debris removal and management, evaluation of site contamination, and removal of trapped water (contaminated or not). During this phase, the operators can be exposed to dust and other kinds of hazardous materials contained in the debris. The aim of the activities carried out is to perform an immediate action, focused on avoiding 
accidents related to further collapses of the damaged buildings, often using temporary structures that serve as structural reinforcement and as protection for the surrounding area. In these situations, it is crucial to analyze and adopt risk reduction activities, design emergency plans, and to consider that the jobs performed include even more risks as compared with normal construction sites. Due to the frequent lack of information in a post-emergency situation, the survey operations conducted in these contexts must gather information useful to define, as much as possible, the condition of the damaged artifacts or affected territories, and therefore it is important to understand the geometry of the surveyed object; the localization, extension and nature of damages; the lacking functionalities and the actual mechanical properties of the damaged materials; and take immediate action to ensure the structural stability of the endangered buildings and the safety of their surroundings.

Non-critical construction sites, which include those building sites that are focused on the reconstruction of the collapsed buildings and the permanent consolidation of the damaged ones, are different. Even if they are in an area where a disaster happened, they usually take place after that the cleanup activities and the debris assessment have been completed, and therefore for those reasons the risk connected to the disaster itself should be already mitigated or eliminated. They can be defined as non-critical construction sites and are mostly associated with ordinary building sites. It is, however, very important to tackle the residual disaster-related risks in advance, as the construction activities in this category are usually carried out by small companies or even property owners with limited knowledge about safety [11], as well it is crucial to always refer to national safety guidelines, best practices, and laws.

\section{Literature Review}

The operations conducted in earthquake-affected areas require special attention to the safety and health of the involved personnel. Search and rescue operations put operators in high risks and hazards. In this context, the use of UAVs can improve the safety of the operators, supporting at the same time the ground logistics and activities. An evaluation of emerging technologies to improve the firefighter capabilities of responding to an emergency has been presented, through a survey-based study by $[12,13]$. Especially the use of UAVs for firefighting operations, with a schematic analysis of the potential usage of drones in different stages of the emergency management cycle has been discussed in [14]. Remotely piloted aircraft systems (RPAS) used by the CNVVF are considered as State aircraft according to article 743 and 744 of the Codice della Navigazione Aerea (Italian Aviation Law) and so are not subject to limitations that occur to normal UAVs. For this reason, UAVs have been, and still are, successfully used in the Italian scenario for disaster management operations.

Apart from the early phases of disaster management, UAVs have also been widely used in post-disaster DA activities, and the subsequent reconstruction phase. The following reference literature has been divided according to the categorization previously done.

\subsection{Use of UAVs at Post-Disaster Construction Sites}

The use of UAVs in the reference literature is not only limited to the emergency phase, since following a disaster, there is always the need to clean up debris, consolidate the damaged built heritage, and assure safe conditions for the operations in the affected area. Technical measures for seismic emergency are special kinds of construction sites that are usually placed after seismic events, and the execution of works therein are coordinated by the CNVVF and the Civil Protection. It is, in fact, their duty to verify damages and certify the accessibility of buildings after the event. In order to guarantee the safety of the operators, the Italian Nucleo Interventi Speciali-Special Interventions Core (NIS) has drafted an operative procedure for the realization of provisional structures and for securing buildings in a seismic emergency [15]. Even if these structures are designed to resist further structural stresses, the safety of the operators involved in their realization is always considered with careful attention, as they are exposed to risks that cannot be always easily eliminated or reduced. Unfortunately, the studies that focus on identifying and assessing all the safety risks for the involved operators are limited. 
A recent study [11] focused on the development of a safety-risk management plan for recovery after disasters, with the aim of identifying related risks and hazards. A study about the use of UAVs for assisting the design of technical measures for a seismic emergency using photogrammetric techniques has been recently published [16], validating the capabilities of UAVs for reducing the operator's risk exposure during the consolidation of the damages that occurred to the building environment and the architectural heritage. The use of building facade images has also been used for the automatic production of "exposure proxy" layers, to be used for determining buildings footprints and their related floor numbers, in order to provide sensible results in risk assessment when a disaster strikes [17]. Moreover, different considerations are proposed in [18] concerning the use of UAVs for post-natural disaster damage evaluation, both for assisting with logistics and cargo delivery, and for performing post-disaster aerial assessments.

\subsection{Use of UAVs at Non-Critical Construction Sites}

The use of UAVs for safety and health purposes has also been, however, studied and evaluated at non-critical construction sites, and more widely in the building industry. The very first study in this field was published in 2012 by a research group of the Georgia Institute of Technology [19] and this research can be somehow considered the first step towards the application of UAV technology for monitoring safety conditions at construction sites. A heuristic analysis (a usability study) has been conducted on the use of a small quadcopter with a video camera and a remote communication device which allows the safety manager and the construction workers to communicate with each other. Another research group from the University of Florida and the University of Nebraska-Lincoln conducted a study about the investigation of the potential application of UAVs to enhance the safety inspection procedures and for outlining the ideal application scenarios [8]. Another study has been conducted by a group of researchers from the Federal University of Bahia which aimed to evaluate the performance of UAVs on safety inspection procedures based on a photo and video database acquired by flights performed at two construction sites in Brazil [9]. Furthermore, this promising line of research was followed by the development of guidelines for incorporating safety assessment from UAVs in the project's safety management routine [20]. These guidelines were developed based on a survey conducted to better understand safety managers' opinions about using UAVs in various safety-related operations [21] and an experiment that considered the possibilities offered by online free and open-source three-dimensional (3D) viewers for sharing the 3D model of the construction sites generated using UAV photogrammetric acquisitions performed over time [22].

\section{Materials and Methods}

In order to identify the requirements of the ideal platform and the related user expectations, a survey was drafted, with the aim of evaluating parameters like effectiveness, importance, and frequency concerning the use of UAVs for performing safety assessment at post-disaster and non-critical construction sites. The survey was composed of 79 questions which consisted of 7 questions concerning age, sex, education, year of working experience, and region of provenience, and 72 technical questions divided into 9 sections. Responses were collected from 32 professionals who operate in the sector of safety at construction sites in Italy. Questions were related to the effectiveness, frequency, and importance that should characterize the use of UAVs in certain situations, together with the onboard sensors that should be used during the operations. The questions reported in the survey were taken from [8,9], with the specific aim of allowing a comparison of user needs in different geographic regions and different regulation contexts. The principal limit of the reference literature was that the survey involved a relatively small population of 22 and 12 interviewed professionals as compared with the relative higher number of this study. The survey focused on activities, sensors, functionalities, and flight conditions that can affect, based on the professional's experience, the use of UAVs in the proposed scenarios. In each section, a 6-point Likert scale was used, apart from the last section, in which a 5-point Likert scale was adopted (to make the results comparable with the reference study). 
For each item, a relative importance index (RII) has been reported, which is a number ranged from 0 to 1 , obtained by dividing the average score related to that item by the maximum value of the adopted Likert scale. This value is reported both for the population surveyed in this study (sample A) and the population surveyed in [8,9] (sample B). The differences in the relative position for a given item between the results obtained in this contribution and the reference results $(\Delta)$ have also been reported which enabled making some quick considerations not only related to different rules and regulation, but also related to the different perceptions about the use of UAVs for performing safety tasks by the different professionals. The results obtained in this contribution were gathered in Italy and are compared with a population of 22 professionals surveyed in USA [8], and (for the very last section) with a population of 12 professionals surveyed in Brazil [9]. The surveyed population has an average age of 43 years and an average working experience of 15 years. The ratio between men and women is 7 to 1 ( 28 men and 4 women). The schooling level is globally high: more than $2 / 3$ of the surveyed population held either a bachelor's degree or a master's degree.

\section{Results}

The first part of the survey contained some questions selected from the reference literature. The first 16 questions referred to some dangerous situations that could be mitigated using UAVs. Answers were based on a six-point Likert scale. People were asked at which level of efficiency and frequency a UAV could be used for the different activities proposed (Table 1). It emerged that the three most dangerous situations where the use of UAVs could be helpful were "conducting post-accident investigation", "using boom vehicles/cranes in the proximity of overhead power lines", and "inspecting at-risk rigging operation". Situations that, instead, resulted in not being suitable for the use of a UAV are those that usually require a deep and on-person analysis by the safety manager, such as "inspecting requirements for guarding machinery", "appropriate usage of tagout and lockout" and inspecting ergonomics requirements".

Table 1. Effectiveness, frequency, and importance factor for the use of unmanned aerial vehicles (UAVs) at construction sites.

\begin{tabular}{cccc}
\hline Activity & A RII & B RII & \multicolumn{1}{c}{$\boldsymbol{\Delta}$} \\
\hline Conducting post-accident investigation & 0.67 & 0.62 & +3 \\
Using boom vehicles and cranes in proximity of overhead power lines & 0.62 & 0.62 & +3 \\
Inspecting at-risk rigging operation & 0.60 & 0.44 & +10 \\
Working near unprotected edge/opening & 0.59 & 0.67 & -2 \\
Working in blind spot of heavy equipment & 0.59 & 0.65 & -2 \\
Inspecting proper usage of fall protection systems & 0.58 & 0.60 & +1 \\
Inspecting housekeeping & 0.57 & 0.61 & -1 \\
Working in proximity of hazardous materials & 0.57 & 0.57 & 0 \\
Working at unprotected trench & 0.56 & 0.57 & 0 \\
Inspecting proper usage of PPE on the site & 0.55 & 0.55 & 0 \\
Working in proximity of boomed vehicles/cranes & 0.53 & 0.67 & -10 \\
Inspecting requirements for ladder/ scaffold & 0.53 & 0.52 & 0 \\
Inspecting confined space entry & 0.49 & 0.52 & -2 \\
Inspecting requirements for guarding machinery & 0.45 & 0.40 & 0 \\
Appropriate usage of tagout/lockout & 0.39 & 0.29 & +1 \\
Inspecting ergonomics requirements & 0.38 & 0.35 & -1 \\
\hline
\end{tabular}

${ }^{1}$ Reference data from [8]. Reproduced from [8], ASCE: 2016.

Concerning the technical aspects of the platform, there were 16 questions in the second section regarded the ideal functionalities and sensors that the UAV should have in order to operate safety assessments (Table 2).

It emerged that the three most important features were "high-resolution mapping capability", "high-precision indoor navigation", and "simple-natural interactive user interface". The three less 
interesting characteristics were "real-time audio communication", "compatibility with other mobile devices", and "manipulator and/or effector".

Table 2. Importance of some technical features of an ideal UAV for conducting safety-related tasks.

\begin{tabular}{cccc}
\hline Technical Features and Sensors & A RII & B RII $\mathbf{1}^{\mathbf{\Delta}}$ \\
\hline High-resolution mapping capability & 0.90 & 0.71 & +12 \\
High-precision indoor navigation & 0.87 & 0.73 & +10 \\
Simple-natural interactive user interface & 0.86 & 0.83 & +4 \\
Sense and avoidance & 0.85 & 0.88 & -1 \\
Actuated video camera & 0.84 & 0.87 & 0 \\
Real-time video communication & 0.84 & 0.90 & -6 \\
Portability & 0.84 & 0.82 & +2 \\
High-precision outdoor navigation & 0.83 & 0.89 & -6 \\
Ruggedness/durability & 0.82 & 0.88 & -5 \\
Actuated non-video sensor packages (thermographic) & 0.81 & 0.62 & +6 \\
Actuated non-video sensor packages (motion detection) & 0.80 & 0.68 & +3 \\
Unattended deployment and return & 0.79 & 0.79 & -3 \\
Autopilot & 0.75 & 0.75 & -3 \\
Real-time audio communication & 0.75 & 0.75 & -3 \\
Compatibility with other mobile devices & 0.72 & 0.85 & -9 \\
Manipulator and/or effector & 0.68 & 0.63 & -1 \\
\hline${ }^{1}$ Referes data from [8] Reproducd from [8] ASCE: 2016 & &
\end{tabular}

${ }^{1}$ Reference data from [8]. Reproduced from [8], ASCE: 2016.

Interviewed professionals were also asked to give information about some operative variables, such as height, distances, times, and locations, for using a UAV for performing safety assessment surveys (Tables 3 and 4 ).

Table 3. Ideal height and location for performing safety operation tasks.

\begin{tabular}{cccc}
\hline Height & A RII & B RII $^{\mathbf{1}}$ & $\boldsymbol{\Delta}$ \\
\hline height $<30 \mathrm{~m}$ & 0.73 & 0.78 & 1 \\
$30 \mathrm{~m}<$ height $<60 \mathrm{~m}$ & 0.7 & 0.8 & -1 \\
$60 \mathrm{~m}<$ height $<120 \mathrm{~m}$ & 0.58 & 0.67 & 0 \\
$120 \mathrm{~m}<$ height & 0.48 & 0.49 & 0 \\
\hline Location & A RII & B RII $^{\mathbf{1}}$ & $\boldsymbol{\Delta}$ \\
\hline Inaccessible/unapproachable locations & 0.88 & 0.8 & 1 \\
Indoor locations & 0.67 & 0.4 & 0 \\
Outdoor locations & 0.83 & 0.96 & -1 \\
\hline
\end{tabular}

${ }^{1}$ Reference data from [8]. Reproduced from [8], ASCE: 2016.

Table 4. Ideal time and distance for performing safety operation tasks.

\begin{tabular}{cccc}
\hline Time & A RII & B RII $^{\mathbf{1}}$ & $\boldsymbol{\Delta}$ \\
\hline time $<30 \mathrm{~min}$ & 0.72 & 0.8 & -1 \\
$30 \mathrm{~min}<$ time $<1 \mathrm{~h}$ & 0.74 & 0.72 & 1 \\
$1 \mathrm{~h}<$ time $<2 \mathrm{~h}$ & 0.61 & 0.52 & 0 \\
$2 \mathrm{~h}<$ time & 0.54 & 0.45 & 0 \\
\hline Distance & A RII & B RII $^{\mathbf{1}}$ & $\boldsymbol{\Delta}$ \\
\hline distance $<150 \mathrm{~m}$ & 0.67 & 0.78 & 0 \\
$150 \mathrm{~m}<$ distance $<1.5 \mathrm{~km}$ & 0.67 & 0.63 & 0 \\
$1.5 \mathrm{~km}<$ distance $<8 \mathrm{~km}$ & 0.57 & 0.39 & 0 \\
$8 \mathrm{~km}<$ distance & 0.48 & 0.38 & 0 \\
\hline
\end{tabular}

${ }^{1}$ Reference data from [8]. Reproduced from [8], ASCE: 2016. 
Results show that the preferred operative height is $30 \mathrm{~m}$, the ideal flight time is about 30 to $60 \mathrm{~min}$, and the optimal distance from the operator is less than $150 \mathrm{~m}$.

In the end, 25 more questions have been analyzed and three categories (based on the line of sight distance) regroup some items that are usually verified in an ordinary safety checklist (Table 5).

Table 5. Relative importance index for UAV safety inspection tasks based on acquisition distances.

\begin{tabular}{|c|c|c|c|}
\hline Overview & A RII & B RII ${ }^{1}$ & $\Delta$ \\
\hline State of all equipment, material, and personnel traffic routes & 0.71 & 0.83 & +1 \\
\hline Perimeter fencing & 0.69 & 0.85 & -1 \\
\hline Erosion control & 0.69 & 0.73 & +3 \\
\hline Parking and emergency evacuation routes & 0.66 & 0.75 & +1 \\
\hline Material laydown areas & 0.64 & 0.78 & -1 \\
\hline Rebar and formwork preassembly area & 0.62 & 0.82 & -3 \\
\hline Waste containers provided & 0.59 & 0.73 & 0 \\
\hline Medium Altitude View & A RII & B RII ${ }^{1}$ & $\Delta$ \\
\hline Workers protected from falling & 0.78 & 0.87 & 0 \\
\hline Safety nets or planked floors & 0.72 & 0.85 & 0 \\
\hline Ramps or runways protected by guardrails and free of obstruction & 0.68 & 0.85 & 0 \\
\hline Workers wearing protective equipment & 0.68 & 0.75 & 0 \\
\hline Waste removed by chutes closed & 0.62 & 0.73 & 0 \\
\hline Close up View & A RII & B RII ${ }^{1}$ & $\Delta$ \\
\hline Lifting loads protected by fall & 0.70 & 0.78 & +6 \\
\hline Aerial work platform protected by guardrails & 0.69 & 0.87 & -1 \\
\hline Isolation of the area of crane operation & 0.67 & 0.72 & +8 \\
\hline Exposed pieces of reinforcing steel capped & 0.67 & 0.87 & -2 \\
\hline Assembly and disassembly of the forms & 0.66 & 0.85 & -2 \\
\hline Scaffolding is plumb and square, an with cross bracing & 0.65 & 0.82 & -1 \\
\hline Working areas free of waste and detritus & 0.64 & 0.78 & +1 \\
\hline Area on refueling and maintenance of equipment & 0.59 & 0.83 & -4 \\
\hline Heavy equipment & 0.59 & 0.72 & +3 \\
\hline The stalls for sand and gravel are close to the concrete mixer and winch & 0.57 & 0.78 & -1 \\
\hline Cargo handling area signaling & 0.57 & 0.80 & -5 \\
\hline Stocks of materials are close to the winch or cranes & 0.56 & 0.75 & -2 \\
\hline Stocks of materials are protected from rain & 0.56 & 0.67 & 0 \\
\hline
\end{tabular}

${ }^{1}$ Reference data from [9]. Reproduced from [9], IGLC: 2016.

From the received answers it is possible to observe that the most important factors are "state of all equipment, material, and personnel traffic routes"; "perimeter fencing"; and "erosion control" (Overview). For the medium altitude view, there is a sensibility towards "workers protected from falling", "safety nets or planked floors", and "ramps or runways protected by guardrails and free of obstruction". The last section (close up view) shows that it has been registered as a high RII for "lifting loads protected by fall", "aerial work platform protected by guardrails", and "isolation of the area of crane operation".

\section{Discussion}

The discussion is based on a comparison between the results of the survey obtained in this study (sample A) with the results gathered from the reference literature (sample B). Although there are some differences between the samples (related to different concepts of safety in the home country of the interviewed professionals and to different regulation environments concerning the use of UAVs) the results obtained were quite similar, and analogies and differences are compared and discussed below. 
Concerning effectiveness, frequency, and importance factors that characterize the use of UAVs at construction sites, it is possible to observe that sample A is more interested than that of sample B in inspecting at-risk rigging operations and less interested in assessing works in the proximity of boomed vehicles and cranes. In both cases, there is interest in using UAVs in those situations in which a different point of view (POV) might be helpful for ensuring safety conditions and avoiding accidents. There is a common trend in sample A and sample B to use UAVs for conducting post-accident investigations, and therefore this could mean that the surveyed samples look at the UAV technology as a tool for assessing accidents, instead of a tool for tackling risks and eliminate hazards.

Considering the importance of the technical features that an ideal UAV should have for conducting safety-related tasks, it emerged that for both sample A and sample B the importance of sense and avoidance is crucial, which is very important because such a feature would allow the platforms to operate indoor, or in the case of flight performed close to lifting loads that could collide with an automatic or semi-automatic flight path. Moreover, sample B prefers the use of a real-time video communication system as compared to sample $\mathrm{A}$, in which the priority is that the platform should be capable of mapping the construction site with a high resolution. An interpretation of this result might lead to the assumption that sample B could be more oriented towards the use of data streamed for real-time inspection purposes, rather than sample A which might prefer a high mapping capability for a deferred use of the gathered data (3D model generation, on-demand inspections, and generation of a "snapshot" of the conditions of the site in a given moment).

Regarding the ideal flight height, location, time, and distance for performing safety operation tasks, it is interesting to note that the ideal parameters expressed by sample A fulfill the current Italian aviation rules for UAV operations. Moreover, compared to the reference surveyed population B, there is a preference for a slightly lower flight altitude, in spite of an increased amount of flight time. This goes together with the preference towards mapping capabilities of the platforms, as a lower flight altitude can provide a higher level of details, both for visual inspections and for mapping purposes. To stress this comparison, and to give a better overview of the limits in the evaluation of the use of UAVs for safety-related tasks at construction sites, the following Table 6 compares some of the main regulation constraints from the Ente Nazionale per l'Aviazione Civile-Italian Civil Aviation Authority (ENAC) amendment "Remotely Piloted Aerial Vehicles Regulation" [23] with the ones reported in the American Federal Aviation Administration (FAA) “Small unmanned aircraft rule (part 107)" [24].

Table 6. Comparison between the regulatory constraints for small unmanned aircraft rule according to the European ENAC regulation and the American Federal Aviation Administration (FAA) regulation.

\begin{tabular}{ccc}
\hline Regulation Constrain & ENAC & FAA $^{\mathbf{1}}$ \\
\hline Max weight & $25 \mathrm{~kg}$ & $25 \mathrm{~kg}$ \\
Allowed flight time & Only during daylight & Only during daylight \\
Pilot assistant & Not mandatory & Not mandatory \\
Max speed & $60 \mathrm{~km} / \mathrm{h}$ in non-critical operation & $160 \mathrm{~km} / \mathrm{h}$ \\
Max height from the terrain & $150 \mathrm{~m}$ & $120 \mathrm{~m}$ \\
Max distance from the pilot & $500 \mathrm{~m}$ & VLOS \\
Visibility from ground control station & VLOS (Visual Line of Sight) & $5 \mathrm{~km}$ \\
Pilot minimum age & 18 years & 16 years \\
Distance from airports & $5 \mathrm{~km}$ & $8 \mathrm{~km}$ \\
Unoffensive UAV & Yes if $<0.3 \mathrm{~kg}$ and with protected rotors & NA \\
Unoffensive upon certification & $<2 \mathrm{~kg}$ and $<60 \mathrm{~km} / \mathrm{h}$ & $\mathrm{NA}$ \\
\hline
\end{tabular}

${ }^{1}$ Expressed in the measurement units of the United States customary system in the source, data reported has been here converted into the International System of Units for allowing a better comparison.

With respect to the last part of the survey which analyzed the relative importance index for UAV safety inspection tasks based on acquisition distances, the professionals of both A and B samples seem to be more interested in monitoring falling from the above risk, especially for what concerns the medium altitude and the close up view. This is supported by the fact that the fall from height is the 
first cause of death in the construction industry, and therefore UAVs might also be used for tackling this critical aspect.

Summarizing the comparison, this contribution further validates the results obtained in [8,9], as there were very few differences with the answers obtained in the framework of this research, as reported in the above discussions. The drafted characteristics of the ideal UAV seems, moreover, to be in line with the current aims of hardware and software development in the UAV industry, and the contributions of this paper could be eventually used to better steer the development of the future platforms in order to satisfy the user needs in these analyzed scenarios.

Although, as it emerged from the survey results, the introduction of the use of UAVs in safety practices may have some advantages, the increasing use of these platforms introduces new risks to people and property on the ground, which have to be carefully assessed and evaluated, as well as the risk related to other parts of the aviation system. A recent European Aviation Safety Agency (EASA) report [25] seeks to identify the main safety risks involving the operation of UAVs, especially addressing the risk of collisions of UAVs with other aircrafts. Another risk assessment procedure published by the Joint Authorities for Rulemaking of Unmanned Systems (JARUS) allows the evaluation of the intended concept of operation [26] and a classification into six diverse specific assurance and integrity levels (SAIL). It is, however, also important to consider the intrinsic risks connected to the use of UAVs in the analyzed scenarios.

In order to accomplish UAV operation, the European Aviation Safety Agency (EASA) asks to recognize and assess active and latent safety threats (as per EASA A-NPA 2015-10). A procedure, called "safety risk assessment" provides the possibility to predict, evaluate, and mitigate the severity and the probability of operational risks.

\section{Safety Risk Assessment Procedure}

As suggested in [27], this procedure can be divided into the following four parts:

1. Safety Hazard Identification: In this part, it is important to identify, via a root cause analysis, the cause of safety hazards and their potential consequences;

2. Safety Risk Assessment: In the second phase, the probability and severity of the consequences are evaluated. It is assigned a value from one to five for the likelihood (where one is extremely improbable and five is frequently), and a value from A to E for the Severity (where A is negligible, and $\mathrm{E}$ is catastrophic). The safety risk assessment matrix, reported in Figure 1, allows determination of whether the safety risks require actions to be undertaken in the next step;

3. Safety Risk Mitigation: For each of the identified risk, colors are assigned for consideration during the risk assessment phase. Red is a not acceptable risk level and require immediate mitigation action, yellow is a tolerable level and the safety risk should be mitigated as low as reasonably practicable, and green is an acceptable situation and no action is required. Actions to perform can be corrective (immediate effects) or preventive (long-term effects) and only when all the risks are mitigated, or accepted, can the operation take place;

4. Safety Documentation: The risk management process must be documented in order to assure the constant development of the risk management procedure for future actions. 


\begin{tabular}{|c|c|c|c|c|c|c|}
\hline \multirow{5}{*}{ 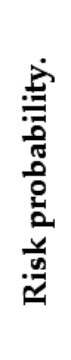 } & 5 & $5 \mathrm{~A}$ & $5 \mathrm{~B}$ & $5 C$ & $5 \mathrm{D}$ & $5 \mathrm{E}$ \\
\hline & 4 & $4 \mathrm{~A}$ & $4 \mathrm{~B}$ & $4 C$ & $4 \mathrm{D}$ & $4 \mathrm{E}$ \\
\hline & 3 & $3 \mathrm{~A}$ & $3 B$ & $3 C$ & $3 D$ & $3 \mathrm{E}$ \\
\hline & 2 & $2 \mathrm{~A}$ & $2 \mathrm{~B}$ & $2 C$ & $2 \mathrm{D}$ & $2 \mathrm{E}$ \\
\hline & 1 & $1 \mathrm{~A}$ & $1 \mathrm{~B}$ & $1 C$ & $1 \mathrm{D}$ & $1 \mathrm{E}$ \\
\hline & & A & B & C & D & E \\
\hline
\end{tabular}

Figure 1. A custom version of the safety risk assessment matrix suggested in [27]. Red is a not acceptable risk level and require immediate mitigation action, yellow is a tolerable level and the safety risk should be mitigated as low as reasonably practicable, and green is an acceptable situation and no action is required. The matrix can be customized according to the organization's safety policy. Reproduced from [27], Drone Industry Insights: 2015.

\section{Conclusions}

The use of UAVs at post-disaster construction sites offers the maximum safety condition for the operators involved in fieldwork operations. Employing low-cost robots, especially unmanned aerial vehicles, guarantees a good compromise between accuracy and operation time whenever the acquisition of metric and non-metric data is required. These systems have widely proven to be affordable and reliable in emergency conditions, especially where there is a need to acquire a large amount of data in a short lapse of time.

Concerning their use at non-critical construction sites, having the possibility to visualize, even from a mobile device, the images of the sites, or generating a 3D model of the yard via a photogrammetric approach, allows performing measurements for evaluating distances that must be respected in order to fulfill the national safety rules. This is a support for risk assessment, especially for nonstandard procedures (i.e., risk assessment in the case of simultaneous procedures that can interfere with each other). High detailed 3D models and high-quality texture can be shared via an open-source platform, allowing a participative design of the safety aspects, both for traditional construction sites and in the context of emergencies.

Some of the possible benefits of using the UAV technology in the considered scenarios are related to their limited operative cost, their fast capability of deployment and response before the ground counterparts, and the reduced exposure of the operator to risks. Some limits are, instead, mainly related to the regulation contexts in which the operation takes places. A summary regarding the benefits and the limits on the adoption of this technology are reported in Table 7.

Table 7. Summary of the benefits and limits of the use of UAVs for the discussed contexts.

\begin{tabular}{|c|c|}
\hline Benefits & Limits \\
\hline Reduce operator exposures to risks and hazards & Flight above people is not always permitted \\
\hline Respond before the intervention of ground logistic & Automatic (or autonomous) flight can be difficult to design \\
\hline Intelligence and reconnaissance operations & Flight above densely populated areas is forbidden \\
\hline $\begin{array}{l}\text { Metric survey and structural damage assessment } \\
\text { can be done via a photogrammetric approach }\end{array}$ & $\begin{array}{l}\text { Flight using a mathematical model for UAV guidance is } \\
\text { not a robust practice }\end{array}$ \\
\hline Limited operative costs & $\begin{array}{l}\text { Flight in BVLOS (Beyond Visual Line of Sight) } \\
\text { conditions not always permitted }\end{array}$ \\
\hline
\end{tabular}


The implementation of UAV technology in the building industry, especially for post-disaster and reconstruction scenarios, can bring several advantages. On the one hand, the possibility of analyzing the construction site from a right-from-above POV gives a wider perspective and the possibility of investigating the details of the site, in order to better identify precarious situations and to plan fieldwork activities in a safer way. On the other hand, one of the biggest challenges to the use of UAVs in the construction industry is to avoid underestimating the hazards introduced from the adoption of unmanned platforms. Future applications might be oriented toward the mitigation of the risk of colliding with structures or operators during unmanned safety assessments.

As the population surveyed in this study is mainly located in Italy, future research will continue to focus on gathering data from a wider range of experts, from different geographic regions and countries. Although this study has not been conducted on a worldwide scale, it validates the previously published studies, and provides a meaningful way to understand new safety operator's needs and concerns with respect to the use of UAV technology in the considered scenarios. Future efforts in this field will further focus on the development of know-how and lessons learned, with the feedback from professionals and public safety operators who will start implementing UAV technology in their everyday working practices.

Author Contributions: A.C. wrote the manuscript, designed the project objectives, collected the data, and defined the structure of this paper.

Funding: This research received no external funding.

Acknowledgments: The author would like to acknowledge the interviewed professionals and experts for answering the survey reported in this publication.

Conflicts of Interest: The author declares no conflict of interest.

\section{References}

1. United Nations Office for Disaster Risk Reduction (UNISDR). Sendai Framework for Disaster Risk Reduction 2015-2030. In Proceedings of the Asian Ministerial Conference on Disaster Risk Reduction 2018, Ulaanbaatar, Mongolia, 3-6 July 2018.

2. United Nations Office for Disaster Risk Reduction (UNISDR). Hyogo Framework for Action 2005-2015: Building the Resilience of Nations and Communities to Disasters; UNISDR: Geneva, Switzerland, 2010.

3. Shan, X.; Peng, J.; Kesete, Y.; Gao, Y.; Kruse, J.; Davidson, R.A.; Nozick, L.K. Market Insurance and Self-Insurance through Retrofit: Analysis of Hurricane Risk in North Carolina. ASCE-ASME J. Risk Uncertain. Eng. Syst. 2017, 3. [CrossRef]

4. Copernicus Emergency Management Service|Copernicus Ems-Mapping. Available online: https: //emergency.copernicus.eu/mapping/list-of-components/EMSR177 (accessed on 23 April 2019).

5. Copernicus Emergency Management Service|Copernicus Ems-Mapping. Available online: https: //emergency.copernicus.eu/mapping/list-of-components/EMSR190 (accessed on 23 April 2019).

6. 2016 Central Italy Earthquake Sequence. Available online: http://www.geerassociation.org/index.php/ component/geer_reports/?view=geerreports\&layout=build\&id=76 (accessed on 23 April 2019).

7. Feliziani, F.; Lorusso, O.; Bernabei, G.; Ricci, A. L'esperienza operativa dei SAPR nelle attività del CNVVF durante il sisma in Italia Centrale 2016/2017. ASITA 2017, 515-518. Available online: http://atti.asita.it/ ASITA2017/Pdf/180.pdf (accessed on 23 April 2019).

8. Gheisari, M.; Esmaeili, B. Unmanned Aerial Systems (UAS) for Construction Safety Applications. In Proceedings of the Construction Research Congress 2016, San Juan, Puerto Rico, 31 May-2 June 2016; pp. 2642-2650.

9. Costa, D.B.; De Melo, R.R.S.; Álvares, J.S.; Bello, A.A. Evaluating the performance of unmanned aerial vehicles for safety inspection. In Proceedings of the 24th Annual Conference of the International Group for Lean Construction, Boston, MA, USA, 20-22 July 2016; pp. 23-32.

10. Esworthy, R.; Schierow, L.-J.; Copeland, C.; Luther, L.; Ramseur, J.L. Cleanup after Hurricane Katrina: Environmental Considerations. Congressional Research Service, Library of Congress: Washington, DC, USA, 2005. 
11. Fardhosseini, M.S.; Esmaeili, B.; Wood, R. A Strategic Safety-Risk Management Plan for Recovery After Disaster Operations. In Proceedings of the International Construction Specialty Conference of the Canadian Society for Civil Engineering (ICSC), Vancouver, BC, Canada, 7-10 June 2015.

12. Schlauderer, S.; Overhage, S.; Weidinger, J. New vistas for firefighter information systems? towards a systematic evaluation of emerging technologies from a task-technology fit perspective. In Proceedings of the 49th Hawaii International Conference on System Sciences (HICSS), Koloa, HI, USA, 5-8 January 2016; pp. 178-187.

13. Weidinger, J.; Schlauderer, S.; Overhage, S. The Good, the Bad and the Indispensable-Insights into the Practical Potential of Emergency Response Information Systems and Drones for Firefighters. In Proceedings of the 51st Hawaii International Conference on System Sciences (HICSS 2018), Waikoloa Village, HI, USA, 2-6 January 2018; pp. 55-64.

14. Kristensen, A.S. Use of Drones for Firefighting Operations. Master's Thesis, Aalborg University, Esbjerg, Denmark, 2019.

15. Grimaz, S.; Malisan, P.; Bolognese, C.; Ponticelli, L.; Cavriani, M.; Mannino, E.; Munaro, L. The short-term countermeasures system of the Italian national fire service for post-earthquake response. Boll. Geofis. Teor. Ed. Appl. 2016, 57, 161-182.

16. Calantropio, A.; Chiabrando, F.; Spanò, A. Impiego di tecniche di fotogrammetria digitale speditiva a supporto delle opere provvisionali negli interventi tecnici in emergenza sismica. Boll. SIFET Soc. Ital. Fotogramm. E Topogr. 2018, 3, 1-10.

17. Iannelli, G.; Dell'Acqua, F. Extensive Exposure Mapping in Urban Areas through Deep Analysis of Street-Level Pictures for Floor Count Determination. Urban Sci. 2017, 1, 16. [CrossRef]

18. Ruiz Estrada, M.A. How Unmanned Aerial Vehicles-UAV's-(or Drones) Can Help in Case of Natural Disasters Response and Humanitarian Relief Aid? Procedia Comput. Sci. 2017, 149, 375-383. [CrossRef]

19. Irizarry, J.; Gheisari, M.; Walker, B.N. Usability assessment of drone technology as safety inspection tools. Electron. J. Inf. Technol. Constr. 2012, 17, 194-212.

20. De Melo, R.R.S.; Costa, D.B.; Álvares, J.S.; Irizarry, J. Applicability of unmanned aerial system (UAS) for safety inspection on construction sites. Saf. Sci. 2017, 98, 174-185. [CrossRef]

21. Gheisari, M.; Esmaeili, B. Applications and requirements of unmanned aerial systems (UASs) for construction safety. Saf. Sci. 2019, 118, 230-240. [CrossRef]

22. Calantropio, A. L'utilizzo dei Droni per la Sicurezza nei Cantieri e negli Interventi Tecnici in Emergenza Sismica; Politecnico di Torino: Eindhoven, The Netherlands, 2017.

23. ENAC. Regolamento (Regulation) Mezzi Aerei a Pilotaggio Remoto (Remotely Piloted Aerial Vehicles) Courtesy English Translation; ENAC: Toulouse, France, 2018.

24. FAA. Part 107 Summary; FAA: Washington, DC, USA, 2016.

25. EASA. Report UAS Safety Risk Portfolio and Analysis; EASA: Cologne, Germany, 2016.

26. JARUS. Guidelines on Specific Operations Risk Assessment (SORA). 2017. Available online: http://jarusrpas.org/sites/jarus-rpas.org/files/jar_doc_06_jarus_sora_v2.0.pdf (accessed on 23 April 2019).

27. Wackwitz, K.; Boedecker, H. Safety Risk Assessment for UAV Operation. Drone Ind. 2015. Available online: https://miningquiz.com/pdf/Drone_Safety/Safety-Risk-Assessment-for-UAV-Operation-Rev.-1.1. compressed.pdf (accessed on 23 April 2019).

(C) 2019 by the author. Licensee MDPI, Basel, Switzerland. This article is an open access article distributed under the terms and conditions of the Creative Commons Attribution (CC BY) license (http://creativecommons.org/licenses/by/4.0/). 